\title{
Smoke in the river: an AEROCLO-sA case study
}

Cyrille Flamant ${ }^{1}$, Marco Gaetani ${ }^{1,2,3}$, Jean-Pierre Chaboureau ${ }^{4}$, Patrick Chazette ${ }^{5}$, Juan Cuesta ${ }^{2}$, Stuart J. Piketh ${ }^{6}$, and Paola Formenti ${ }^{2}$

${ }^{1}$ Laboratoire Atmosphère Milieux Observations Spatiales (LATMOS)/IPSL, UMR CNRS 8190, Sorbonne Université, UVSQ, Paris, France

${ }^{2}$ Université de Paris and Univ Paris Est Creteil, CNRS, LISA, F-75013 Paris, France

${ }^{3}$ Scuola Universitaria Superiore IUSS, Pavia, Italy

${ }^{4}$ Laboratoire d'Aérologie (LAERO), UMR CNRS 5560, Université de Toulouse, Toulouse, France

${ }^{5}$ Laboratoire des Sciences du Climat et de l'Environnement (LSCE)/IPSL, UMR CNRS 1572, CEA, UVSQ, Gif-sur-Yvette, France

${ }^{6}$ School of Geo- and Spatial Science, North-West University, Potchefstroom, South Africa

Correspondence to: Cyrille Flamant (cyrille.flamant@latmos.ipsl.fr)

\section{Supplementary Figures}

(a)

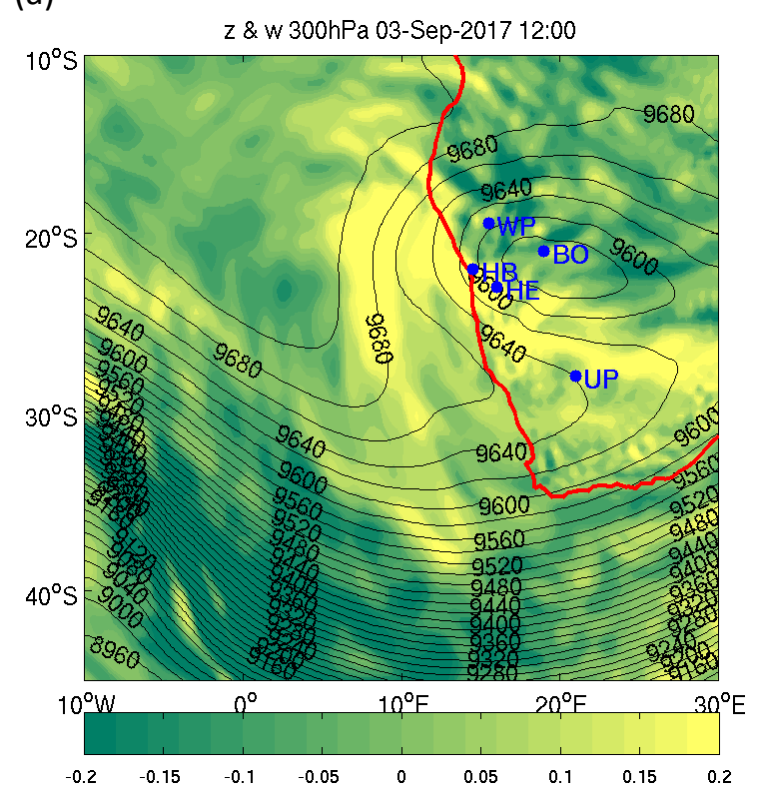

(b)

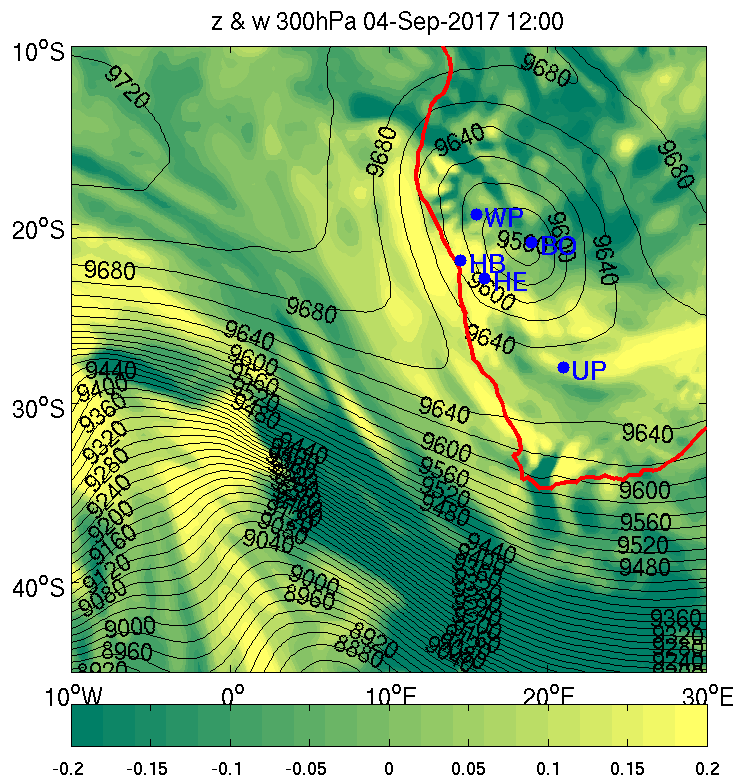

Figure S1: Geopotential ( $\mathrm{m}$, contours) and vertical velocity $\omega$ ( $\mathrm{hPa} \mathrm{s}^{-1}$, colour) at $300 \mathrm{hPa}$ at 1200 UTC on (a) 3 September and (b) 4 September 2017, from ERA5 reanalysis. The names of the instrumented sites appear in blue (from north to south): WP is Windpoort, BO is Bonanza, HB is Henties Bay, HE is HESS (Namibia) and UP is Upington (South Africa). 
a)

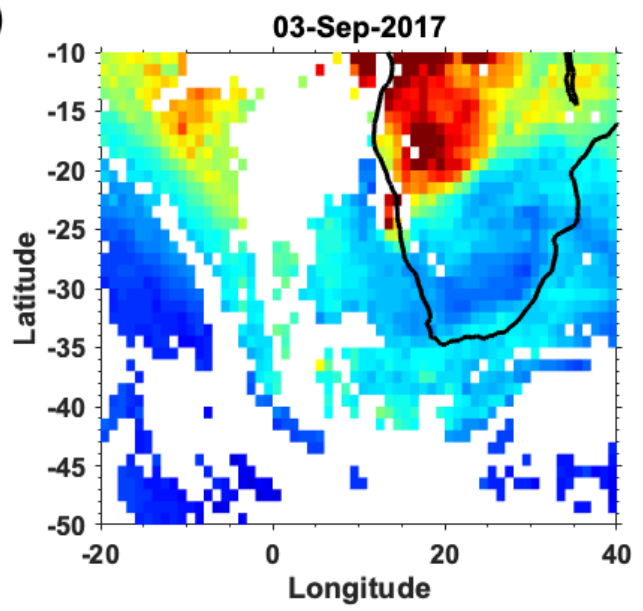

c)

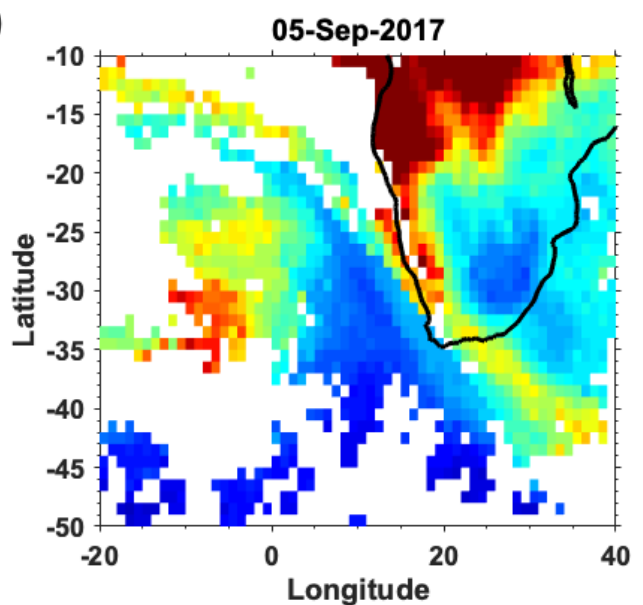

molecules $\mathrm{cm}^{-2}$ ) - IASI

b)

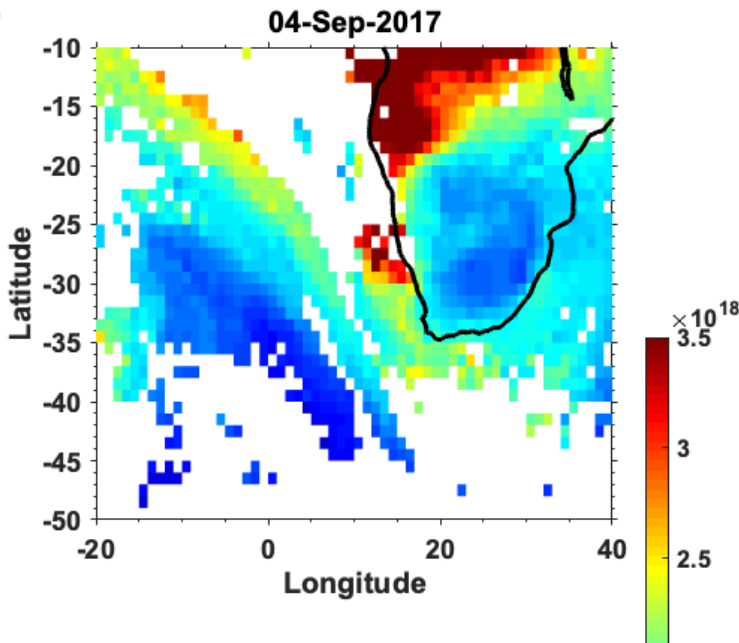

d)

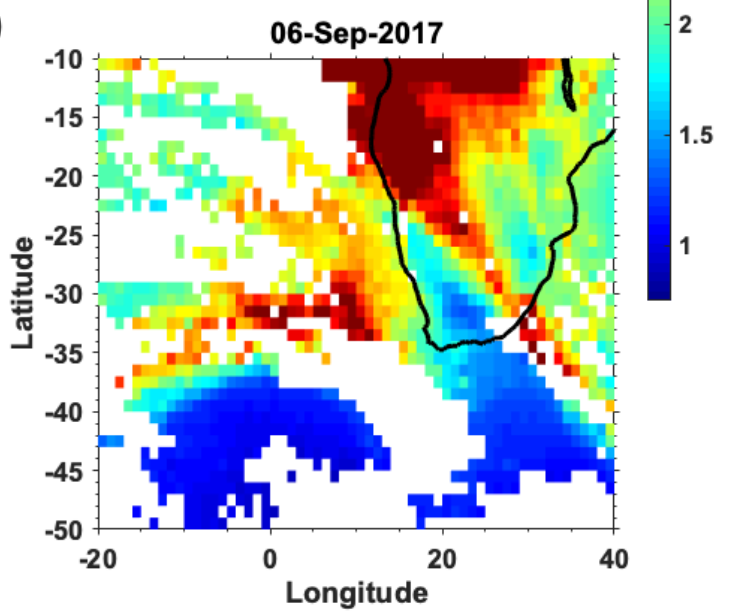

Figure S2: IASI-derived total column amounts of CO from 3 to 6 September 2017 (a-d). Daytime measurements from the IASI instruments onboard MetOp-A and MetOp-B satellites are merged together, overpassing the region respectively around $09 \mathrm{~h} 00$ and $08 \mathrm{~h} 30$. Blanks are shown for thick clouds, whereas IASI CO retrievals are performed for cloud-free conditions and also above relatively thin low and mid-level clouds. 
(a)

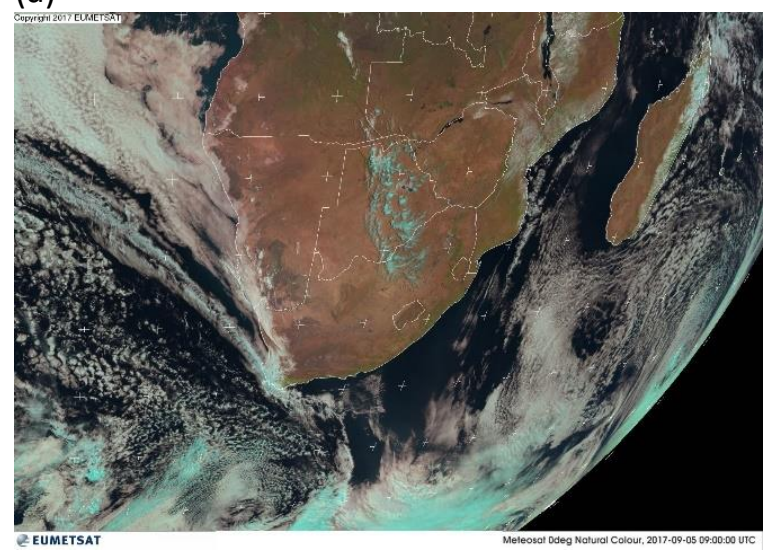

(c)

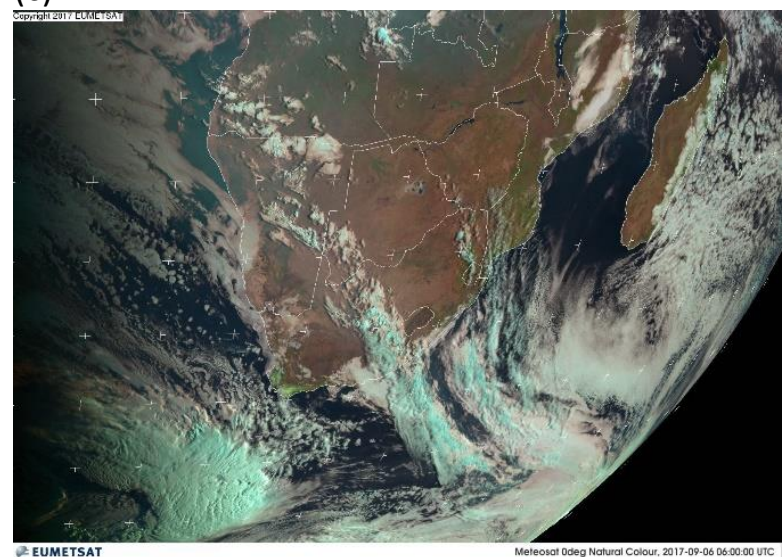

(b)

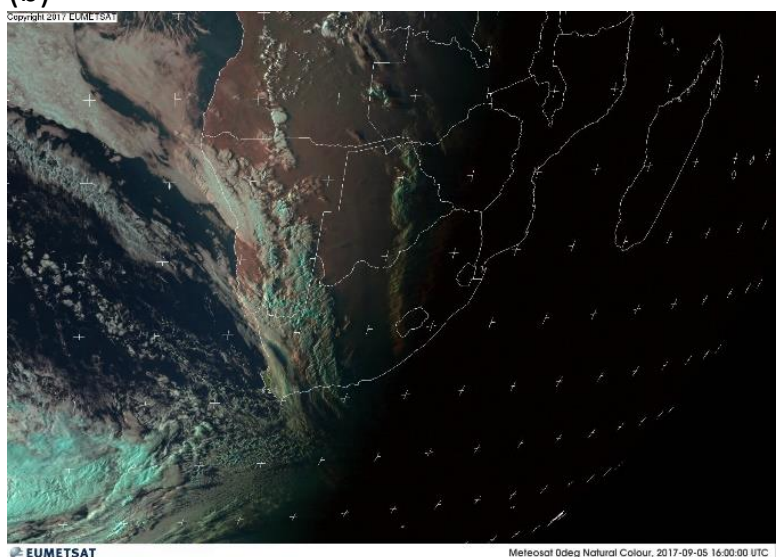

(d)

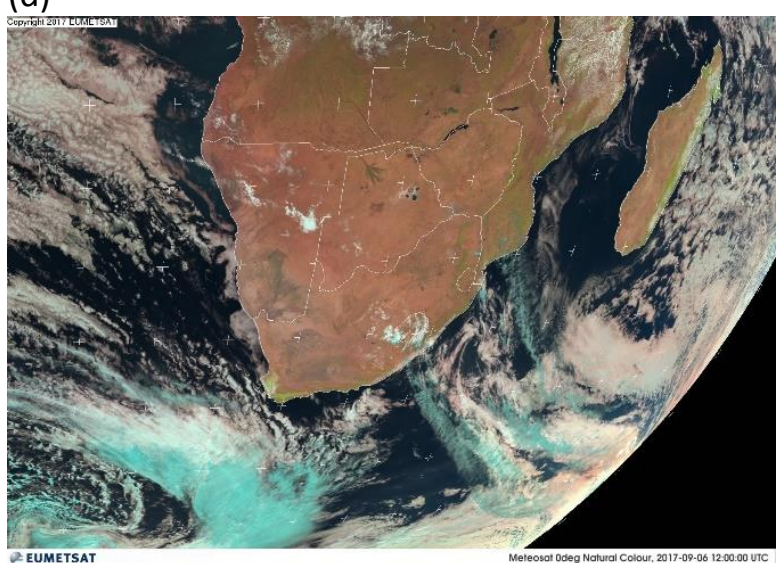

Figure S3: SEVIRI true colour images over southern Africa on 5 September 2017 at (a) 0900 UTC and (b) 1600 UTC, and on 6 September 2017 at (c) 0600 UTC and (d) 1200 UTC. Map Credit: (C EUMETSAT. 
GFED4s biomass burning carbon emissions g C/day/m2

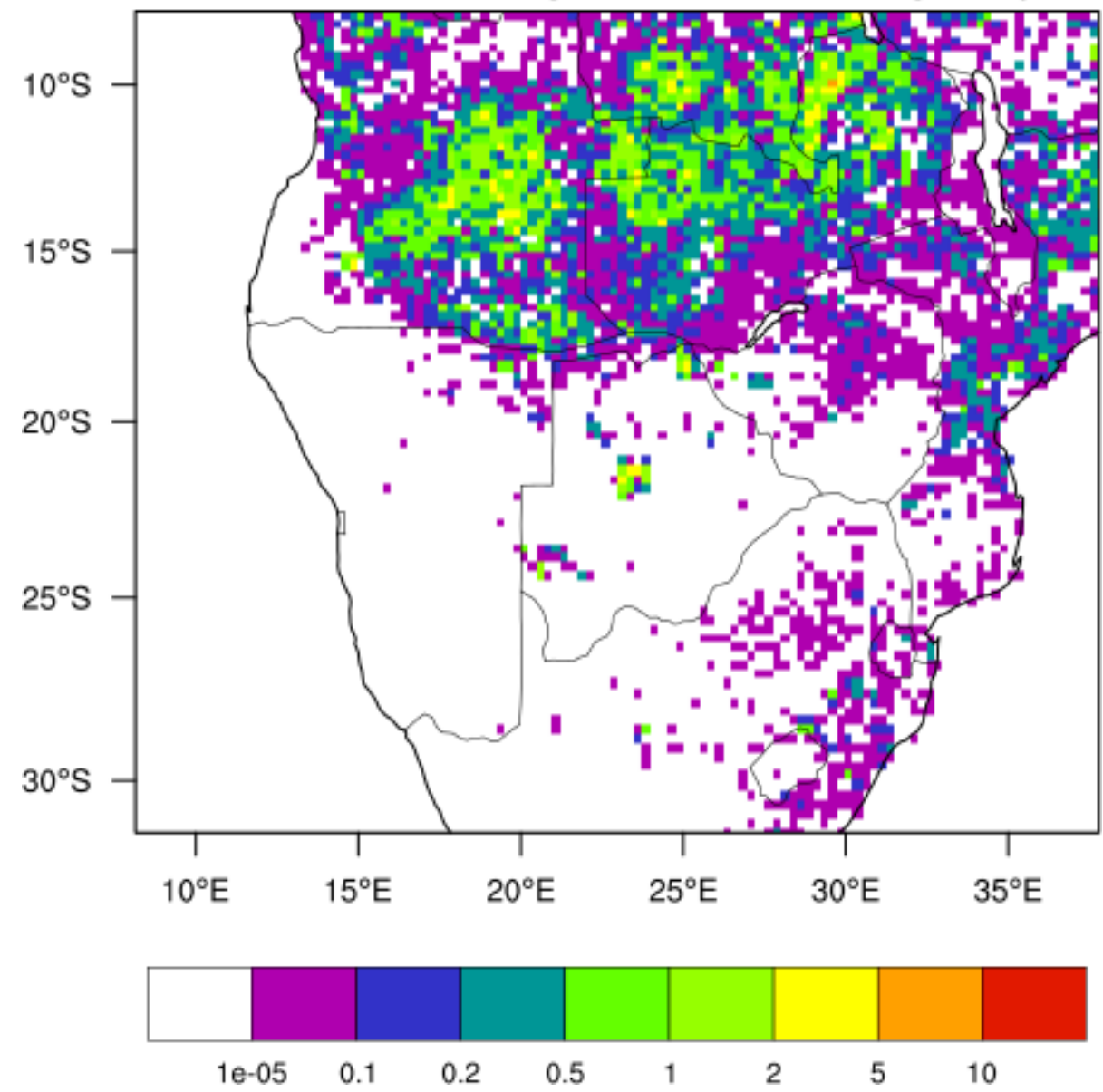

Figure S4: GFED4s inventory for biomass burning carbon emissions $\left(\mathrm{g} \mathrm{C} \mathrm{day}{ }^{-1} \mathrm{~m}^{-2}\right.$ ) over southern Africa between 1 and 6 September 2017. 

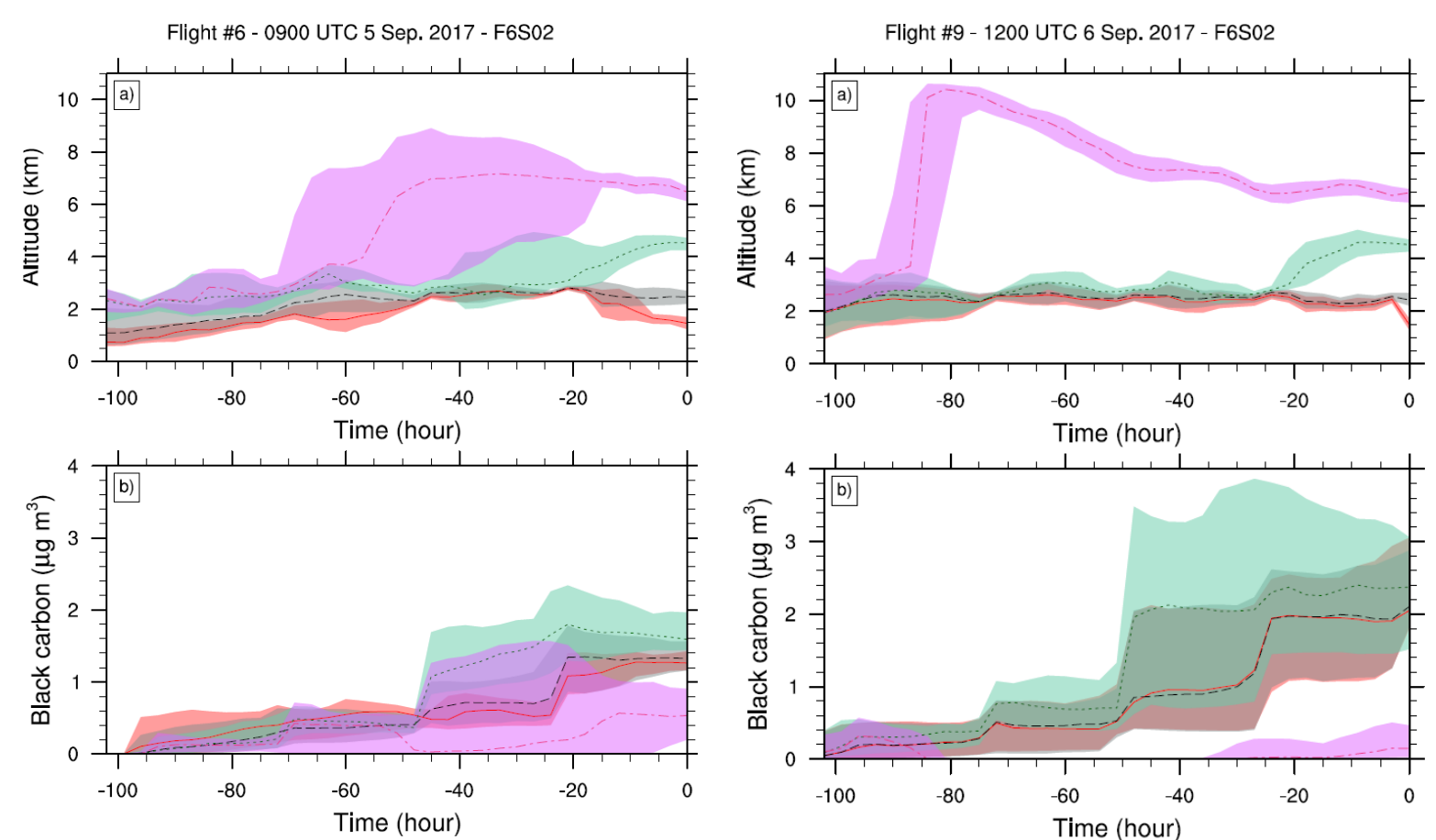

Figure S5: 102-h evolution of (a) altitude of and (b) black carbon concentration along back trajectories ending at the F06 flight track at 0900 UTC 5 September 2017 and at altitude between (purple) 6 and $7 \mathrm{~km} \mathrm{AMSL}$, (green) 4 and $5 \mathrm{~km} \mathrm{AMSL}$, (grey) 2 and $3 \mathrm{~km} \mathrm{AMSL}$ and (red) 1 and $2 \mathrm{~km}$ AMSL. The dotted lines show the median value and the shaded contours the range between the first and the third quartiles. (c) and (d), as in (a) and (b) but ending at 1200 UTC 6 September 2017 for the F09 flight track. 
(a)

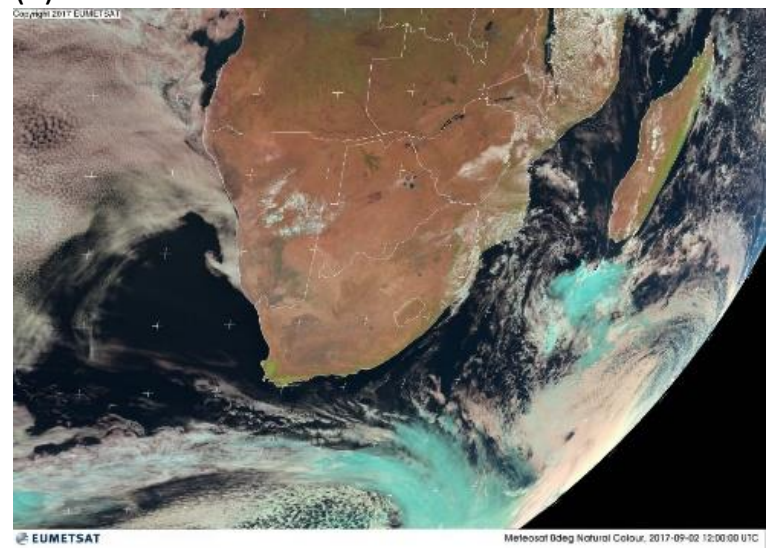

(c)

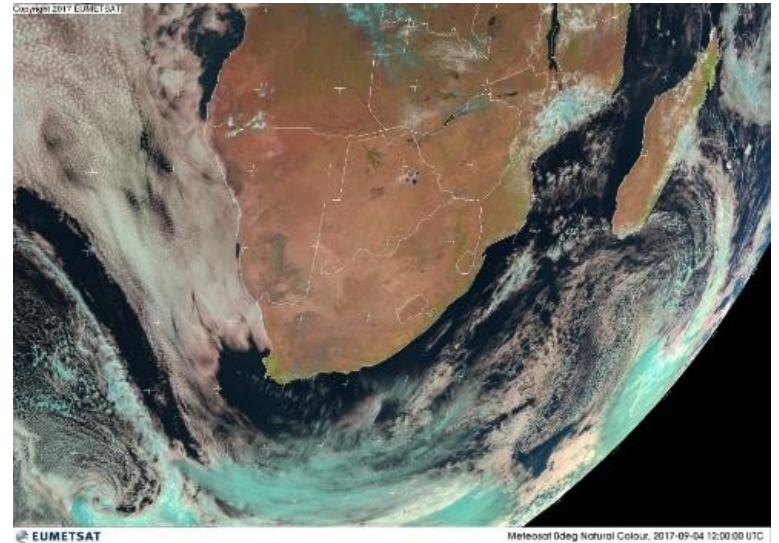

(b)

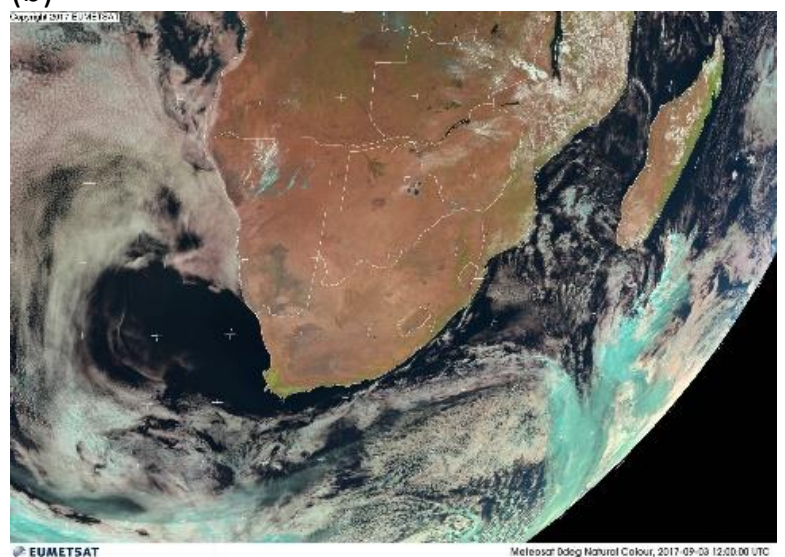

(d)

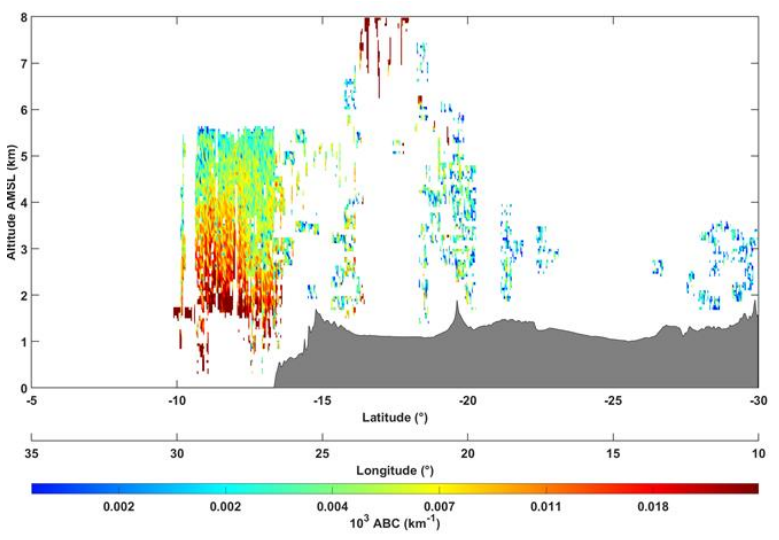

Figure S6: SEVIRI true colour images over southern Africa at 1200 UTC on (a) 2 September, (b) 3 September and (c) 4 September 2017. (d) Total attenuated backscatter coefficient from the spaceborne lidar CATS between 13:07 and 13:23 UTC on 4 September 2017. Map Credit: (C) EUMETSAT. 